\title{
Antibiotic use and population ecology: How you can reduce your "resistance footprint"
}

\author{
David M. Patrick MD MHSc, James Hutchinson MD
}

$\infty$ See related commentary by Nicolle and colleagues, page 371, and related review paper by Mulvey and Simor, page 408

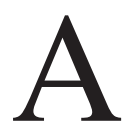

n 8-year-old child presents with a 4-day history of a nonproductive cough and a temperature of $38^{\circ} \mathrm{C}$.

Her chest is clear, except for some wheezing. She has no tachypnea or tachycardia. The child's father is deeply concerned. What would be the harm of prescribing antibiotics for acute bronchitis? Even when antimicrobials are used wisely, they create selective pressure that may increase the prevalence of antibiotic-resistant organisms. Every antibiotic prescription represents a balance of benefits and risks, both to the individual and the population. The risks of antimicrobial therapy to the patient are well-known and include hypersensitivity, drug interaction and disruption of normal flora. ${ }^{1,2}$ However, not all of the risks associated with antibiotic use may be directly experienced by the patient receiving treatment.

The metaphor "tragedy of the commons" describes an event in which individuals acting locally to benefit themselves inadvertently contribute to catastrophe at the ecological level. This metaphor originates from a description of the tragic collective outcome incurred by farmers who individually contributed to over-grazing of common lands. Indeed, this metaphor can be applied to antimicrobial use. What is the parallel problem with prescribing antibiotics for acute bronchitis in a previously healthy child? Just as the farmer who attempts to benefit from adding 1 more animal to the pasture does not consider the impending catastrophe of complete consumption of the pasture, the prescribing physician or patient who attempts to benefit from antibiotic therapy likely does not consider the impending catastrophe of antibiotic resistance. Examination of the population perspective of antibiotic resistance requires consideration of how our individual actions sum over a population to create a measurable effect on antibiotic resistance. Our collective prescriptions constitute an ecological problem that may reduce the success of future therapy. In this article, we provide an overview of some of the abundant literature that documents this effect.

During a clinical encounter is not the easiest time to stand back and consider our relationship with microorganisms in the broadest sense, along the evolutionary time scale and across the entire population. Microbes and multicellular animals have engaged in a co-evolutionary tango for hundreds of millions of years. ${ }^{4}$ Natural selection is the engine that created our current pageant of diverse and complex life on earth. This dance has refined our immune system, led to the

\section{Key points}

- Genes that determine resistance to antibiotics were widespread in nature even before humans discovered the use of these drugs.

- There is ecological, observational and experimental evidence to suggest that populations with lower rates of antibiotic use will generally experience a lower burden of colonization by antibiotic-resistant organisms.

- Physicians can contribute to decreased antibiotic prescribing and prevalence of resistant organisms by carefully following evidence-based guidelines.

- The medical profession needs to engage governments to assist in striking the best balance between controlling antibiotic use through formulary restrictions and making antibiotics available to those who can truly benefit.

establishment of highly beneficial normal flora and caused remarkable adaptation of man to microbe and vice versa. The process of natural selection also ensures that if a substance affects an organism's chance of survival, those best able to reproduce and thrive in the presence of the substance will propagate, increase in prevalence and become more dominant in the microbial population over time. Chemical competition among microorganisms has occurred for hundreds of millions of years and has resulted in the production of antimicrobial compounds long before humans walked the earth. ${ }^{5.6}$ Because many antimicrobials in use by humans were derived from these substances, bacteria were endowed with rich genetic machinery to resist the effects of antibiotics long before Domagk and Fleming discovered sulfa drugs and penicillin in the first half of the twentieth century. Many of these genes can be transferred horizontally between species and are important evolutionary elements in their own right. Such mechanisms are well documented in the laboratory where it is possible to observe natural selection at the level of the microbial population. ${ }^{7-9}$

Physicians depend on antibiotics for many good reasons, even while knowing that their use carries a long-term evolutionary cost. Drawing a parallel to carbon emissions and global warming, we may well ask how we may reduce our "resistance footprint" without causing harm by withholding

From the University of British Columbia and the BC Centre for Disease Control (Patrick), Vancouver, BC; and Memorial University and Eastern Health (Hutchinson), St. John's, NL 
antibiotics from those that need them. There is plenty of room for action based on current knowledge, but we are going to have to make a concerted effort to change our own habits.

\section{Population-level effect of prescribing on antibiotic resistance}

In recent years, there has been a vast improvement in our ability to measure antibiotic use at the population level, track trends in resistance and identify the relations between use, resistance and outcomes of disease. ${ }^{10,11}$ As an example, Figure 1 illustrates the remarkable concordance between the increasing rate of fluoroquinolone use and the increasing rate of ciprofloxacin resistance among uropathogens in British Columbia.

Table 1 summarizes the studies supporting the hypothesis that increasing levels of population use of many drugs and drug classes corresponds with increasing resistance among pathogens. These papers were identified by searching MEDLINE for the keywords "antibiotic," "resistance" and "utilization" and by screening the results for articles that focused on observations of association in entire populations rather than on individual institutions. Ecological studies, which measure both resistance and use at the population level rather than the individual or institutional level, demonstrate that the spatial and temporal distribution of resistance is strongly associated with the rate of use of specific classes of antibiotics in human populations. ${ }^{12-20}$ These studies show a clear association between the use of penicillins, macrolides and fluoroquinolones and drug resistance in common human pathogens like Streptococcus pneumoniae and between the use of fluoroquinolones and resistance in Escherichia coli.

There are also increasing data from individual-level crosssectional studies, cohort studies and randomized controlled trials that strengthen the causal inference of this relation (Table 1). ${ }^{15,21,22}$ The relation between antibiotic use and resistance satisfies a logical temporal sequence, has been demonstrated in individuals and has even been demonstrated in a randomized controlled trial. ${ }^{22}$ An interesting finding of such studies is that not all drugs of a particular class are equal with respect to their potency in selecting for resistance. ${ }^{23}$ For example, azithromycin has a long terminal elimination half-life. ${ }^{24} \mathrm{Al}-$ though this has proven convenient from a dosing point of view, the downside is that there is a great deal of time at the end of a course of therapy when the drug is still present in the body at subinhibitory concentrations. Several studies indicate that azithromycin is far more likely to select for macrolide resistance than drugs of the same class with shorter half-lives..$^{18-21}$

Finally, there is also strong ecological evidence that deliberate efforts to control antimicrobial use can have beneficial effects on the trajectory of resistance. ${ }^{12,18,25}$ It appears that populations that use antibiotics prudently are benefiting.

The question of whether the relation between antibiotic use and resistance at the population level is causal is not straightforward or easily answered. However, application of the 9 Bradford Hill criteria for the evaluation of environmental factors and relation to disease strongly supports causality. ${ }^{26}$ There is a reasonably strong statistical association and consis- tency across populations. There is relative specificity of the effect, a logical temporal sequence of exposure followed by effect, and evidence of a biological gradient or a doseresponse relation. This relation is entirely plausible based on known biological mechanisms and is coherent with other observed effects of evolution. Probably most important, there is experimental evidence both in laboratories and in groups of humans that helps assure that our view is not entirely obscured by unknown confounders.

\section{Reasonable goals in antimicrobial therapy}

Most bacteria are neutral or beneficial from the standpoint of our health. Even those with the potential to be pathogens do not always cause disease. Yet all bacteria are able to mutate or acquire new genetic material. If the resulting genetic modification is heavily favoured by the abundant presence of antimicrobials, our ability to treat disease will be impaired. Some drug advertising and much of our medical training wrongly conceptualizes infectious disease treatment as a "war of extermination." In reality, the purpose of antimicrobial therapy is rarely, if ever, the complete eradication or elimination of microbes from the patient or their environment. Because we are fated to co-exist with microbes, the purpose of antimicrobial therapy must be more appropriately and realistically considered to be the prevention or favourable modification of the course of infectious disease.

\section{Gaps, complexities and confounders}

There remain key gaps in our knowledge about populationlevel effects of antibiotic prescribing on resistance. Most existing studies focus only on widely cultured human pathogens where data are available from diagnostic laboratories in sufficient quantity to allow statistical inference. There is a shortage of observations in large populations for some important

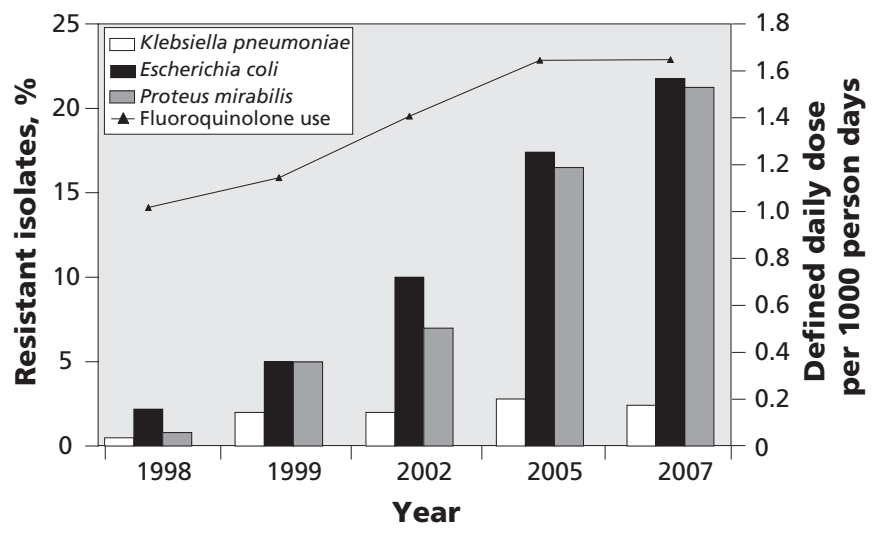

Figure 1: Fluoroquinolone use and correlation to ciprofloxacin resistance among uropathogens in British Columbia. Sources of data: PharmaNet and BC Biomedical Laboratories. Fluoroquinolone use was strongly associated with ciprofloxacin resistance for Klebsiella pneumoniae (Spearman rank test, $p=0.027$ ), Escherichia coli $(p<0.001)$ and Proteus mirabilis $(p<0.001)$. 
categories of human pathogens. However, data available from hospitals and institutions, although not reflective of the general population in all respects, strongly broaden the argument that our practice affects our future with respect to a wide array of antibiotic-resistant organisms. ${ }^{27-29}$

Just as the natural relations between microorganisms, animals, humans and the environment are exquisitely complicated, it is expected that the effects of wide-scale, man-made distribution of antimicrobials on microorganisms will be complicated. We are just beginning to understand the contribution to evolution of horizontally transferable genetic elements. Because these movable pieces of DNA may confer resistance to more than 1 class of antibiotic, the use of 1 class of antimicrobials may select for resistance to another, and resistance could conceivably increase even with declining use of some classes of drugs. ${ }^{30}$
Host factors will also prove important. The density of human populations is an independent predictor of the prevalence of antibiotic resistance. ${ }^{31}$ With or without antimicrobial selection, some newly introduced microbial clones are very fit to spread through human populations. Although antibiotic use may contribute to an environment that favours the spread of community-associated methicillin-resistant Staphylococcus aureus in North America, the strains also possess other attributes that facilitate their spread and pathogenicity. ${ }^{32}$

Although it is a legitimate focus for physicians, use of antimicrobials by humans is not the only source of selective pressure. The massive use of antibiotics for both therapeutic purposes and growth promotion in the agriculture and food industries and in veterinary medicine are reasons for concern. ${ }^{33}$ Such use could result in colonization of humans by re-

Table 1: Evidence that antibiotic use at the population level is associated with antibiotic resistance

\begin{tabular}{|c|c|c|}
\hline Level; study design & What the studies show & Example \\
\hline \multicolumn{3}{|l|}{ Community level } \\
\hline \multirow[t]{7}{*}{ Ecological studies } & \multirow{7}{*}{$\begin{array}{l}\text { - Antibiotic use is associated } \\
\text { with the prevalence } \\
\text { of carriage of resistant } \\
\text { organisms in the } \\
\text { community. }\end{array}$} & $\begin{array}{l}\text { - Resistance of Streptococcus pneumoniae to penicillin was correlated with } \\
\text { the use of } \beta \text {-lactam antibiotics and macrolides across Europe. }{ }^{12}\end{array}$ \\
\hline & & $\begin{array}{l}\text { - In Europe, the prevalences of resistance to macrolides and } \beta \text {-lactams } \\
\text { in S. pneumoniae, macrolide resistance in Streptococcus pyogenes } \\
\text { and resistance to quinolones and co-trimoxazole in Escherichia coli were } \\
\text { significantly correlated with the use of relevant classes of antibiotics. }{ }^{13}\end{array}$ \\
\hline & & $\begin{array}{l}\text { - Antibiotic use (within the past year) and population density were independent } \\
\text { predictors of S. pneumoniae antibiotic resistance in Belgium. }{ }^{14}\end{array}$ \\
\hline & & - Antibiotic use correlates with carriage of resistant S. pneumoniae in Iceland. ${ }^{15}$ \\
\hline & & $\begin{array}{l}\text { - Associations are most consistent if a } 2 \text {-year lag is observed between antibiotic } \\
\text { use and resistance trends (multiple countries). }{ }^{16}\end{array}$ \\
\hline & & $\begin{array}{l}\text { - The prevalence of fluoroquinolone-resistant } E \text {. coli was associated with } \\
\text { the rate of fluoroquinolone use in Spain.19 }\end{array}$ \\
\hline & & $\begin{array}{l}\text { - The prevalence of fluoroquinolone-resistant } E \text {. coli in hospitals was associated } \\
\text { with the rate of fluoroquinolone use in the surrounding community. }\end{array}$ \\
\hline \multicolumn{3}{|l|}{ Individual level } \\
\hline $\begin{array}{l}\text { Cross-sectional } \\
\text { study }\end{array}$ & $\begin{array}{l}\text { - Use of antibiotics by } \\
\text { individuals is associated } \\
\text { with a higher rate } \\
\text { of carriage of resistant } \\
\text { organisms. }\end{array}$ & $\begin{array}{l}\text { - Individual-level antibiotic use correlates with the carriage of antibiotic- } \\
\text { resistant S. pneumoniae in Iceland. } .^{15}\end{array}$ \\
\hline $\begin{array}{l}\text { Randomized } \\
\text { controlled trial }\end{array}$ & $\begin{array}{l}\text { - Use of antibiotics by } \\
\text { individuals is associated } \\
\text { with a higher risk of } \\
\text { subsequent colonization } \\
\text { by a resistant strain. }\end{array}$ & $\begin{array}{l}\text { - Use of macrolides increased the carriage of macrolide-resistant } \\
\text { S. pneumoniae by } 50 \% \text {. The effect was larger with longer-acting macrolides } \\
\text { than with shorter-acting macrolides. }\end{array}$ \\
\hline
\end{tabular}


sistant organisms through a variety of routes. Residual antibiotics in meat eaten by humans may lead to selection for resistance among colonizing organisms in the human host. Most food producers in developed countries observe a wash-out period to reduce this risk. Selection of resistant organisms in food animals and pets can lead to colonization of humans with the same strain. ${ }^{34}$ Resistant commensal organisms may not carry disease but they may carry horizontally transferable genetic elements that could transfer resistance to other human commensal organisms or pathogens. Finally, excess antibiotics spilled into the environment from the agriculture and food industries could lead to selection of resistant organisms in the environment that could subsequently spread disease or resistance to humans.

\section{What are the major reasons for prescribing antibiotics?}

None of us would feel very comfortable managing pneumonia, pyelonephritis or spreading cellulitis without antibiotics. Fortunately, prescriptions for these serious infections account for a small fraction of overall antibiotic use. The majority of outpatient prescribing is for the acute respiratory conditions pharyngitis, sinusitis and acute bronchitis, as well as for otitis media. ${ }^{35}$ These syndromes are almost entirely caused by viruses. Several systematic reviews and meta-analyses have concluded that there is little or no benefit of antibiotics to these conditions. ${ }^{36}$ Rates of antibiotic prescriptions for these indications need to drop. A key ex-

\section{Box 1: Evidence-based strategies to reduce your} "resistance footprint"

- Reduce or eliminate the prescribing of antibiotics for acute bronchitis if pneumonia is not a concern. ${ }^{41}$

- Use a delayed prescription strategy (do not recommend antibiotics to healthy children unless their symptoms do not improve within 48 hours). Do not prescribe antibiotics for simple myringitis or otitis media with effusion. $^{38}$

- Avoid the use of drugs with a greater propensity to select for resistant bacteria, such as azithromycin. ${ }^{18,21}$

- Consider alternatives to fluoroquinolones, such as nitrofurantoin, when treating cystitis. ${ }^{39}$

- Reserve the use of respiratory fluoroquinolones for unresponsive community-acquired pneumonia or pneumonia in high-risk patients (those with asthma, lung cancer, chronic obstructive pulmonary disease, diabetes, renal or hepatic failure or congestive heart failure). ${ }^{40}$

- Vaccinate with influenza and pneumococcal vaccines when indicated to decrease respiratory infections. ${ }^{42}$

ample of early success in this area has been that, in recent years, it has been shown that most cases of otitis media are adequately managed symptomatically, with consideration of antibiotic prescription only with failure to improve over 48 hours. ${ }^{37,38}$ Pediatricians and family physicians have shown that by using such an approach, antibiotic prescriptions can safely be reduced. ${ }^{35}$

Table 2: Impact of population-level interventions on antimicrobial use and resistance

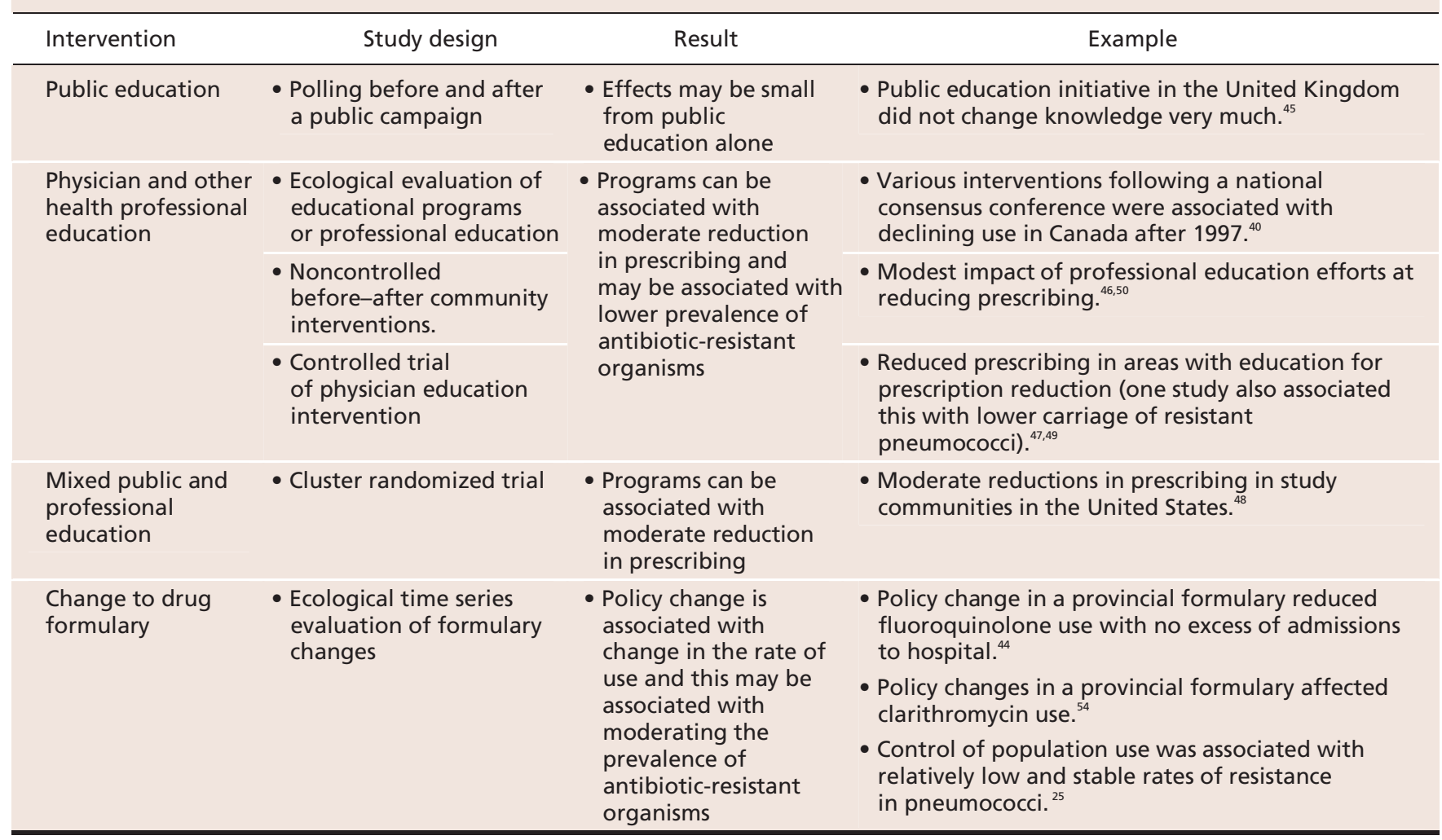




\section{Strategies to reduce your antibiotic resistance footprint}

With the availability of many detailed guidelines for the treatment of specific infections, it is sometimes difficult to identify actions to take at the practice level. A few simple suggestions for reducing unnecessary antimicrobial use are presented in Box 1. In general, a higher threshold for antimicrobial prescriptions should be developed. Such actions do not lie outside of the mainstream literature and are compatible with guidelines for the management of individual infections. ${ }^{36-39}$

Physicians may be concerned that avoidance of antibiotic use could lead to more infectious complications or hospital admissions. Indeed, when surveyed, some physicians and patients do not agree with strategies such as delayed prescribing. ${ }^{43}$ This is why it is critical to construct guidelines for use and nonuse based on rigorous reviews of the evidence. However, there are some reassuring data available. Restriction of fluoroquinolones on the prescription drug formulary for Ontario was not associated with a net change in hospital admissions, and the rate of hospital admissions for gastrointestinal complications was actually decreased. ${ }^{44}$ Re-evaluation of patients during the course of an infection to look for improvement or deterioration is an important aspect of medical care as we improve the judicious use of antimicrobials.

\section{Physicians and the regulation of antibiotics}

Evaluations of efforts to curb prescribing and resistance at population level are summarized in Table 2. These articles were identified by searching MEDLINE for the keywords "antibiotic," "resistance" and "utilization," and by screening the results for articles that focused on interventions in entire populations rather than individual institutions Reductions in antibiotic use through such programs, although measurable, are modest, ${ }^{45-50}$ One review concluded that there was some benefit from social marketing, practice guidelines, authorization systems and peer review with feedback, and speculated that online systems that provide clinical information, structured order entry, and decision support may be the most promising approach. ${ }^{51}$

A book developed as part of the "Do Bugs Need Drugs?" program in British Columbia and Alberta represent important initiatives to create understanding among doctors and patients about the importance of reducing antimicrobial misuse..$^{52,53}$ Evaluation of the approach suggested by this program is underway.

\section{Conclusion}

It is becoming clear that the greatest successes in changing patterns of antibiotic use have resulted from administrative decisions, such as changes to drug formularies at the institutional level or changes in reimbursement from provincial drug plans. ${ }^{44,54}$ Such approaches will prove necessary to adequately steward the use of the drugs that we have. As a profession, we would do well to thoroughly engage in discussions and processes in this area as a means of assuring the best interests of our patients while reducing our collective resistance footprint.
This article has been peer reviewed.

Competing interests: None declared.

Contributors: Both of the authors contributed to the conception, design, analysis and interpretation of data. Both of the authors drafted the article, revised it for important intellectual content and approved the version submitted for publication.

Acknowledgements: We thank the Michael Smith Foundation for Health Research for funding our tracking of drug use and resistance in British Columbia, the British Columbia College of Pharmacists for providing of data on antibiotic use, Dr. Dale Purych and BC Biomedical Laboratories for providing data on antimicrobial resistance trends. We thank Dr. Fawziah Marra, Mei Chong and Elaine Fuertes for data analysis and figure production, and Gillian McMillan and Rebecca Hall for manuscript preparation.

\section{REFERENCES}

1. Hoban DJ. Antibiotics and collateral damage. Clin Cornerstone 2003; Suppl 3:S12-20.

2. Baldo BA, Zhao Z, Pham NH. Antibiotic allergy: immunochemical and clinical considerations. Curr Allergy Asthma Rep 2008;8:49-55.

3. Hardin G. The tragedy of the commons. Science 1968;162:1243-8.

4. Dawkins R. Climbing mount improbable. New York (NY): Norton; 1996.

5. de la Cruz F, Davies J. Horizontal gene transfer and the origin of species: lessons from bacteria. Trends Microbiol 2000;8:128-33.

6. Rowe-Magnus DA, Guerout AM, Ploncard P, et al. The evolutionary history of chromosomal super-integrons provides an ancestry for multiresistant integrons. Proc Natl Acad Sci USA 2001;98:652-7.

7. Woodford N, Ellington MJ. The emergence of antibiotic resistance by mutation. Clin Microbiol Infect 2007;13:5-18.

8. Tenover FC. Development and spread of bacterial resistance to antimicrobial agents: an overview. Clin Infect Dis 2001;Suppl 3:S108-15.

9. Droge M, Puhler A, Selbitschka W. Horizontal gene transfer as a biosafety issue: a natural phenomenon of public concern. J Biotechnol 1998;64:75-90.

10. Hutchinson JM, Patrick DM, Marra F, et al. Measurement of antibiotic consumption: A practical guide to the use of the Anatomical Therapeutic Chemical classification and Defined Daily Dose system methodology in Canada. Can J Infect Dis 2004;15:29-35.

11. Patrick DM, Marra F, Hutchinson J, et al. Per capita antibiotic consumption: How does a North American jurisdiction compare with Europe? Clin Infect Dis 2004;39:11-7.

12. Bronzwaer SL, Cars O, Buchholz U, et al. A European study on the relationship between antimicrobial use and antimicrobial resistance. Emerg Infect Dis 2002;8:278-82.

13. Goossens H, Ferech M, Vander SR, et al. Outpatient antibiotic use in Europe and association with resistance: a cross-national database study. Lancet 2005;365:579-87.

14. Van Eldere J, Mera RM, Miller LA, et al. Risk factors for development of multiple-class resistance to Streptococcus pneumoniae strains in Belgium over a 10-year period: antimicrobial consumption, population density, and geographic location. Antimicrob Agents Chemother 2007;51:3491-7.

15. Arason VA, Kristinsson KG, Sigurdsson JA, et al. Do antimicrobials increase the carriage rate of penicillin resistant pneumococci in children? Cross-sectional prevalence study. BMJ 1996;313:387-91.

16. Mera RM, Miller LA, White A. Antibacterial use and Streptococcus pneumoniae penicillin resistance: A temporal relationship model. Microb Drug Resist 2006;12:158-63.

17. Livermore DM, Reynolds R, Stephens $\mathrm{P}$, et al. Trends in penicillin and macrolide resistance among pneumococci in the UK and the Republic of Ireland in relation to antibiotic sales to pharmacies and dispensing doctors. Int J Antimicrob Agents 2006;28:273-9. Epub 2006 Sep 14.

18. Arason VA, Sigurdsson JA, Erlendsdottir H, et al. The role of antimicrobial use in the epidemiology of resistant pneumococci: A 10-year follow up. Microb Drug Resist 2006;12:169-76.

19. Gobernado M, Valdes L, Alos JI, et al. Antimicrobial susceptibility of clinical Escherichia coli isolates from uncomplicated cystitis in women over a 1-year period in Spain. Rev Esp Quimioter 2007;20:68-76.

20. MacDougall C, Powell JP, Johnson CK, et al. Hospital and community fluoroquinolone use and resistance in Staphylococcus aureus and Escherichia coli in 17 US hospitals. Clin Infect Dis 2005;41:435-40.

21. Vanderkooi OG, Low DE, Green K, et al. Predicting antimicrobial resistance in invasive pneumococcal infections. Clin Infect Dis 2005;40:1288-97.

22. Malhotra-Kumar S, Lammens C, Coenen S, et al. Effect of azithromycin and clarithromycin therapy on pharyngeal carriage of macrolide-resistant streptococci in healthy volunteers: a randomised, double-blind, placebo-controlled study. Lancet 2007;369:482-90.

23. Dagan R, Barkai G, Leibovitz E, et al. Will reduction of antibiotic use reduce antibiotic resistance? The pneumococcus paradigm. Pediatr Infect Dis J 2006;25:981-6.

24. Girard AE, Girard D, English AR, et al. Pharmacokinetic and in vivo studies with azithromycin (CP-62,993), a new macrolide with an extended half-life and excel- 
lent tissue distribution. Antimicrob Agents Chemother 1987;31:1948-54.

25. Molstad S, Erntell M, Hanberger H, et al. Sustained reduction of antibiotic use and low bacterial resistance: 10-year follow-up of the Swedish Strama programme. Lancet Infect Dis 2008;8:125-32.

26. HILL AB. The environment and disease: Association or causation? Proc $R$ Soc Med 1965;58:295-300

27. Gould IM. Antibiotic policies to control hospital-acquired infection. J Antimicrob Chemother 2008;61:763-5.

28. Fishman N. Antimicrobial stewardship. Am J Med 2006;119(6 Suppl 1):S53-61.

29. Owens RC Jr, Rice L. Hospital-based strategies for combating resistance. Clin Infect Dis 2006;42 Suppl 4:S173-81.

30. Lipsitch M, Samore MH. Antimicrobial use and antimicrobial resistance: a population perspective. Emerg Infect Dis 2002;8:347-54.

31. Bruinsma N, Hutchinson JM, van den Bogaard AE, et al. Influence of population density on antibiotic resistance. J Antimicrob Chemother 2003;51:385-90.

32. Boucher HW, Corey GR. Epidemiology of methicillin-resistant Staphylococcus aureus. Clin Infect Dis 2008;Suppl 5:S344-9.

33. McEwen SA. Antibiotic use in animal agriculture: What have we learned and where are we going? Anim Biotechnol 2006;17:239-50.

34. White DG, Zhao S, Sudler R, et al. The isolation of antibiotic-resistant salmonella from retail ground meats. N Engl J Med 2001;345:1147-54.

35. Marra F, Patrick DM, Chong M, et al. Antibiotic use among children in British Columbia, Canada. J Antimicrob Chemother 2006;58:830-9.

36. Ben David D, Rubinstein E. Appropriate use of antibiotics for respiratory infections: review of recent statements and position papers. Curr Opin Infect Dis 2002; 15:151-6.

37. Little P, Gould C, Williamson I, et al. Pragmatic randomised controlled trial of two prescribing strategies for childhood acute otitis media. BMJ 2001;322:336-42.

38. Spurling GK, Del Mar CB, Dooley L, et al. Delayed antibiotics for respiratory infections. Cochrane Database Syst Rev 2007;(4):CD004417.

39. Nicolle L, Anderson PA, Conly J, et al. Uncomplicated urinary tract infection in women. Current practice and the effect of antibiotic resistance on empiric treatment. Can Fam Physician 2006;52:612-8.

40. Conly J. Antimicrobial resistance in Canada. CMAJ 2002;167:885-91.

41. Smucny J, Fahey T, Becker L, et al. Antibiotics for acute bronchitis. Cochrane Database Syst Rev 2004:(4);CD000245.

42. Cohen R. Approaches to reduce antibiotic resistance in the community. Pediatr Infect Dis J 2006;25:977-80.
43. Arroll B, Goodyear-Smith F, Thomas DR, et al. Delayed antibiotic prescriptions: What are the experiences and attitudes of physicians and patients? J Fam Pract 2002;51:954-9.

44. Mamdani M, McNeely D, Evans G, et al. Impact of a fluoroquinolone restriction policy in an elderly population. Am J Med 2007;120:893-900.

45. Parsons S, Morrow S, Underwood M. Did local enhancement of a national campaign to reduce high antibiotic prescribing affect public attitudes and prescribing rates? Eur J Gen Pract 2004;10:18-23.

46. Rubin MA, Bateman K, Alder S, et al. A multifaceted intervention to improve antimicrobial prescribing for upper respiratory tract infections in a small rural community. Clin Infect Dis 2005;40:546-53.

47. Guillemot D, Varon E, Bernede C, et al. Reduction of antibiotic use in the community reduces the rate of colonization with penicillin G-nonsusceptible Streptococcus pneumoniae. Clin Infect Dis 2005;41:930-8. Epub 2005 Aug 29

48. Finkelstein JA, Huang SS, Kleinman K, et al. Impact of a 16-community trial to promote judicious antibiotic use in Massachusetts. Pediatrics 2008;121:e15-23.

49. Perz JF, Craig AS, Coffey CS, et al. Changes in antibiotic prescribing for children after a community-wide campaign. JAMA 2002;287:3103-9.

50. Hennessy TW, Petersen KM, Bruden D, et al. Changes in antibiotic-prescribing practices and carriage of penicillin-resistant Streptococcus pneumoniae: A controlled intervention trial in rural Alaska. Clin Infect Dis 2002;24:1543-50. Epub 2002 May 21.

51. Parrino TA. Controlled trials to improve antibiotic utilization: a systematic review of experience, 1984-2004. Pharmacotherapy 2005;25:289-98.

52. Do Bugs Need Drugs? A community program for wise use of antibiotics. Alberta: Alberta Health and Wellness. Available: www.dobugsneeddrugs.org/ (accessed 2009 Jan. 21).

53. Blondel-Hill E, Fryters S. Bugs and Drugs. Edmonton: Capital Health; 2006.

54. Marra F, Patrick DM, White R, et al. Effect of formulary policy decisions on antimicrobial drug utilization in British Columbia. J Antimicrob Chemother 2005; 55:95-101.

Correspondence to: Dr. David Patrick, Department

of Epidemiology, BC Centre for Disease Control,

655 W 12 Ave., Vancouver BC V5Z 3L5;

fax 604 660-0197; david.patrick@ bccdc.ca 